\title{
Level of stress and work adjustment among medical professionals
}

\author{
Kanchan Pal $^{1, *}$, Parul Gairola ${ }^{2}$, Anita Tyagi ${ }^{3}$, Rani Srivastava ${ }^{4}$ \\ ${ }^{1}$ Post Graduate Student, ${ }^{2}$ PHD. Scholar, ${ }^{3}$ Special Education cum Counselor, ${ }^{4}$ Professor \& Head, Dept. of Clinical, \\ Psychology, Santosh Medical College and Hospital, Ghaziabad, Uttar Pradesh, India.
}

*Corresponding Author:

Email: kanchan01121994@gmail.com

\begin{abstract}
Introduction: Stress in workplace has become an increasingly burning issue over the past few decades. Various stressors in work place reduces productivity, increases mental pressure and make people sick in many ways which is evident by its increasing ratio. Besides it does affect the overall performance at work, memory output, concentration and learning.

Aim and Objective: To study the level of stress, work related stress and adjustment in their profession.

Materials and Methods: A cross-sectional study which is comprising of 95 doctors and study being conducted in a functional hospital of medical college where the Stress reaction checklist and work related stress questionnaire have been administered on working.

Results: There is mild level stress $[15.36( \pm 10.1)]$ shown in Stress Reaction Checklist $(\mathrm{SRC})$ and work stress where senior doctors are showing more stress $[16.36( \pm 10.5)]$ in comparison to junior doctors $[14.51( \pm 9.34)]$. The first stressor of work related stress questionnaire's uncontrollable working situations mean values is $11.99( \pm 6.2)$ on rating how often stressful and $15.62( \pm 10)$ on rating how much stressful as a total sample. The second stressor of work related stress questionnaire's organization of work and working conditions mean value is $11.92( \pm 5.9)$ on the rating of how often stressful and $14.34( \pm 8.34)$ on the rating of how much stressful as a whole sample.

Conclusion: This study has concluded that senior doctors are facing more stress due to some specific stressors like being shouldered for entire departmental responsibilities specially management of medical needs where junior doctors do not bother these stressors. It would be better if they are being given some settled guidelines as how to cope up with stress then their life may become meaningful and they can perform the work with batter efficiency.
\end{abstract}

Keywords: Stress, Work stress, and doctors/Medical professionals.

\section{Introduction}

"Doctors in the medical profession need to deal with the clinical population on a regular basis. Due to spending a considerable amount of time with them; they may be exposed to burnout which reflects their stress and work stress."

Stress in workplace has become an increasingly matter of attention over the past few decades. Presence of stress in workplace reduces productivity, psychological pressure and makes people afflicted in many ways which is evident by many researches. It is found in many studies that stress at work -place affects the overall performance by affecting memory output, concentration and learning. ${ }^{1}$ Stress is a bodily reaction to various known and unknown stressors; as a result it precipitates deleterious consequences to those systems and organs of body thus serious illness can follow. At one time or another, most people experience stress. ${ }^{2}$ The term stress has been used to describe a variety of negative feelings and reactions that accompany threatening or challenging situations. However, not all stress reactions are negative. A certain amount of stress is actually necessary for survival ${ }^{3}$ to understand and clarify the meaning of stress, it is useful to state what does not constitute stress:

1. Stress is not simply anxiety or nervous tension.

2. Stress need not always be demanding.
3. Stress is not always due to overwork but may also result from having too little to do.

4. Stress is body's biological response mechanisms but the body has limited capacity to respond to stressors. ${ }^{4}$

Work stress is caused or made worse by work related demands. It simply refers to when a person perceives his/her work environment in such way that his or her reaction involves feelings of an inability to cope with it. It may be caused by perceived/real pressure/deadlines/threats/anxieties within the working environment. ${ }^{5}$ Stress is defined as "the pattern of specific and non-specific responses an organism makes to stimuli events that disturbs its equilibrium and exceeds its ability to cope". ${ }^{6}$ Being working in a medical setup doctors have to take care of life threatening injuries and illness complicated by overwork, under-staffing, tight schedules, paper work, intricate or malfunctioning equipment, complex hierarchies of authority and skills, dependent and demanding patients and patient's death, all of which are significant contributors to stress. ${ }^{7}$ High exposure to stressful situations/events among medical personnel may manifest itself in several different outcomes including depression, anxiety, self-doubt, posttraumatic stress disorder, loss of sleep, impairing immune function, elevation of cardiovascular risk 
factors, burn out and disturbed relationship with family. ${ }^{8,9}$

\section{Materials and Methods}

A cross-sectional study was conducted in order to assess the level of stress and work stress among senior and junior doctors who are working in various departments of (Medical, Dental and Paramedical health Sciences) of Santosh Medical College \& Hospital of Ghaziabad, U.P. during from October 2017 to March 2018. Ethical clearance was obtained from the Institutional Ethical Committee. Purposive sampling technique was used and a total of 95 doctors were willing to participate in the study. They categorized as consultants /senior residents. ${ }^{46}$ and junior residents. ${ }^{49}$ The entire group of doctors was taken for analysis based on informed consent. Stress level assessed by using Stress Reaction Checklist ${ }^{10}$ and work stress level assessed by using Work Related Stress Questionnaire which is comprising of following categories: Uncontrollable Working Situations (UWS), Organization of work and Working conditions (OW), Conflict of Work and Family roles (W/FC), unfavorable Relationship with Colleagues (RC), Interaction with Patients (IP), Intentions of Leaving Job (ILJ) and Psychosomatic Symptoms (PS). ${ }^{11}$ Statistical mean, Standard deviation, t-test and Correlation by Pearson's method were used for the analysis.

\section{Results and Discussion}

Result Table 1 is showing the mean value and standard deviation of total sample on both questionnaires groupwise and as a whole.

Stress Reaction Checklist (SRC) which shows there is mild level stress. As far as the work stress is concerned, it is found that level of work stress is also above the cutoff points that reflect mild level of work stress as a whole. Detail analysis is as follows:

Stress Reaction Checklist: On the first checklist, that defines the stress level, the mean value of total sample is $15.36( \pm 10.1)$. As group wise the mean value of senior group is $16.36( \pm 10.5)$ and the mean value of junior group is $14.51( \pm 9.34)$. As we know that mean, value indicates the average value. Total sample mean value indicates that all are mild level of stress where senior and junior doctors (both) groups are indicating their mild level of stress towards their work place.

\section{Work Related Stress Questionnaire}

UWS: The first stressor of work related stress questionnaire's uncontrollable working situations mean values is $11.99( \pm 6.2)$ on rating how often stressful and $15.62( \pm 10)$ on rating how much stressful as a total sample. As group wise the mean value is $12.54( \pm 6.59)$ on rating of how often stressful and $17.32( \pm 11.21)$ of senior group of doctors. On junior doctors, the mean value is $11.57( \pm 6.11)$ on the rating of how often stressful and $14( \pm 9.52)$ on the rating of how much stressful. As we can see as a whole mean value indicates that they are facing stressors for sometimes. To be more specific with the same area they are not much stressed. Where senior group is showing occasionally stressful but sometime they do work under pressure. On the other hand, the junior doctors are indicating occasionally work stress but to some extent, they are free to do work. It means these finding compromising with each other.

OW: The second stressor of work related stress questionnaire's organization of work and working conditions mean value is $11.92( \pm 5.9)$ on the rating of how often stressful and $14.34( \pm 8.34)$ on the rating of how much stressful as a whole sample. As group wise the mean value is $13( \pm 5.98)$ on the rating of how often stressful 16.13 (8) on the rating of how much stressful on senior group of doctors. On junior group of doctors, the mean value is $10.97( \pm 5.54)$ on the rating of how often stressful and $12.75( \pm 7.88)$ on the rating of how much stressful. Again, as a whole, they are facing stress for sometimes and they are mildly stressful. Senior doctors are indicating occasionally stress where there are quite unsatisfied while doing work in organization. As far as junior doctors are showing occasional work stress but they are mainly not stressed with organization.

W/FC: The third stressor of work related stress questionnaire's conflict of work and family roles, as a whole; the mean value is $7.74( \pm 4.59)$ on rating of how often stressful and on the rating of how much stressful, the mean value is $9.76( \pm 6.72)$. On senior doctors, the mean value is $8.52( \pm 3.39)$ on the rating of how often stressful and on the rating of how much stressful, the mean value is $10.63( \pm 5.59)$. On junior doctors, the mean value is $7( \pm 4.43)$ one the rating of how often stressful and on the rating of how much stressful, the mean value is $9( \pm 6.28)$. As a whole, it indicates situational conflicts and these situations are mainly not stressful for them. Here, senior doctors indicate to have conflicts occasionally with family and work situations and stressful with more intensity. On the other hand, junior doctors remain occasionally stressed but they are mainly not stressed with this factor.

RC: The forth stressor of work related stress questionnaire's unfavorable relationship with colleagues, the mean value is $7.37( \pm 4.28)$ on the rating of how often stressful and $6.78( \pm 6.45)$ on the rating of how much stressful as a whole. As senior group, the mean value $7.34( \pm 3.56)$ on the rating of how often stressful and on the rating of how much stressful, the mean value is $8.45( \pm 7.39)$. As far as junior group is concerned, the mean value is $7.46( \pm 4.38)$ on the rating of how often and on the rating of how much stressful, the mean value is $9.12( \pm 6)$. As total sample the doctors indicate stress occasionally and they are mainly not stressed. As group wise, both groups indicate they do not have specific issues with their colleagues. 
IP: While interaction with patients, total sample mean value is $6.27( \pm 7.34)$ on the rating of how often stressful and on the rating of how much stressful, the mean value is $7.34( \pm 4.86)$. As group wise, the mean value is $6.39( \pm 3.39)$ on rating of how often stressful and $8( \pm 5.78)$ on the rating of how much stressful on senior doctors. On the other hand, the mean value is $6.22( \pm 3.39)$ on rating of how often stressful and on the rating of how much stressful $6.67( \pm 4.46)$ of junior doctors. As a whole doctors indicate occasional stress while interacting with patients. Senior doctors indicate occasional stress but they are facing stress during IPD and OPD sessions. On the other hand, junior doctors indicate occasionally stress which does not make them influence.

ILJ: Another stressor of work related stress questionnaire is intentions of leaving job where the mean value is $6.16( \pm 2.72)$ as a whole. As group wise, the mean value is $6.54( \pm 2.67)$ of senior doctors. The mean value of junior doctors is $5.87( \pm 2.41)$. It is found that these doctors are at not intended to leave the job but the score is just touching the level probability in future they may be intended.

PS: On this stressors, psychosomatic symptoms; the mean value is $8.93( \pm 7.3)$ as total sample. Group wise, senior doctors' mean value is $11( \pm 9.4)$. On the other hand, junior doctors; mean value is $6.41( \pm 5.5)$. Psychosomatic symptoms assume that while working with the stressing conditions in job people have a possibility to develop physical and psychological discomfort. The scale has observed the possibility of psychosomatic disturbance among doctors. As per scores, it is noticed that they have rare chances of development of psychosomatic symptoms during past.
While comparing scores across both the groups (senior and junior doctors) on the basis oft- test, some of the important findings are as under:

(*) Junior doctors were significantly stressed probably may be due to lack of tolerance $\&$ endurance.

(**) During uncontrollable working situations senior doctors are found to be more influence.

(***) Among junior doctors work stress have made them more sensitive and vulnerable.

(****) While interaction with patients is concerned senior doctors adjustment is more affected. (Table1).

As seen in Fig. I, there is positive correlation of 0.4 between stress and uncontrollable working situations (UWS). This shows that most doctors tend to deal with higher level of stress when sudden or unmanageable situations arises at their workplace. This means that the more uncontrollable work's situations occur the higher level of stress is experienced. This exists for both frequency of occurrence of stress and the intensity of stress experienced. It is a positive correlation of 0.4 between stress and organization with working conditions $(\mathrm{OW})$. This shows that doctors face problem while doing work with workplace that increase their level of stress. This means the more they work at workplace their intensity of stress experienced increases. There is a positive correlation of 0.4 between stress and conflicts between work and family (W/FC). This shows that doctors face stress more not due to work pressure but due to being overworked therefore they hardly get time to spend with their family therefore the intensity of psychological disturbance becomes more. A positive correlation of 0.6 is found between stress and a psychosomatic symptom (PS) which means doctors face physical and psychological problems while working in workplace. This shows that the more they work their psychosomatic symptoms increased.

Table: 1 Showing the mean value and standard value of total sample and group wise (senior and junior) doctors

\begin{tabular}{|c|c|c|c|c|c|c|c|c|c|}
\hline \multirow[t]{2}{*}{ S. No. } & \multirow{2}{*}{\multicolumn{2}{|c|}{ Particulars }} & \multicolumn{2}{|c|}{$\begin{array}{c}\text { Sr. Resident } \\
(\mathrm{N}=46)\end{array}$} & \multicolumn{2}{|c|}{$\begin{array}{c}\text { Jr. Resident } \\
(\mathrm{N}=49)\end{array}$} & \multicolumn{2}{|c|}{ Total $(\mathrm{N}=95)$} & \multirow[t]{2}{*}{$\begin{array}{l}\text { P value } \\
\text { (t Test) }\end{array}$} \\
\hline & & & Mean & SD & Mean & SD & Mean & SD & \\
\hline 1 & \multicolumn{2}{|l|}{ SRC } & 16.36 & 10.50 & 14.51 & 9.34 & 15.36 & 10.10 & $0.3^{*}$ \\
\hline \multirow[t]{2}{*}{2} & \multirow[t]{2}{*}{ UWS } & How of Ten & 12.54 & 6.59 & 11.57 & 6.11 & 11.99 & 6.20 & $0.4^{* *}$ \\
\hline & & How Much & 17.32 & 11.21 & 14.00 & 9.52 & 15.62 & 10.00 & 0.1 \\
\hline \multirow[t]{2}{*}{3} & \multirow[t]{2}{*}{ OW } & How of Ten & 13.00 & 5.98 & 10.97 & 5.54 & 11.92 & 5.90 & 0.0 \\
\hline & & How Much & 16.13 & 8.00 & 12.75 & 7.88 & 14.34 & 8.43 & 0.0 \\
\hline \multirow[t]{2}{*}{4} & \multirow[t]{2}{*}{$\mathrm{W} / \mathrm{FC}$} & How of Ten & 8.52 & 3.39 & 7.00 & 4.43 & 7.74 & 4.59 & 0.1 \\
\hline & & How Much & 10.63 & 5.59 & 9.00 & 6.28 & 9.76 & 6.27 & 0.2 \\
\hline \multirow[t]{2}{*}{5} & \multirow[t]{2}{*}{$\mathrm{RC}$} & How of Ten & 7.34 & 3.56 & 7,46 & 4.38 & 7.37 & 4.28 & $0.8^{* * * *}$ \\
\hline & & How Much & 8.45 & 7.39 & 9.12 & 6.00 & 6.78 & 6.45 & 0.6 \\
\hline \multirow[t]{2}{*}{6} & \multirow[t]{2}{*}{ IP } & How of Ten & 6.39 & 3.39 & 6,22 & 3.69 & 6.27 & 3.67 & $0.8^{* * * * *}$ \\
\hline & & How Much & 8.00 & 5.78 & 6.67 & 4.46 & 7.34 & 4.86 & 0.1 \\
\hline 7 & \multicolumn{2}{|l|}{ ILJ } & 6.54 & 2.67 & 5,87 & 2,41 & 6.16 & 2.72 & 0.2 \\
\hline 8 & \multicolumn{2}{|l|}{ PS } & 11.00 & 9.40 & 6.91 & 5.50 & 8.93 & 7.30 & 0.0 \\
\hline
\end{tabular}




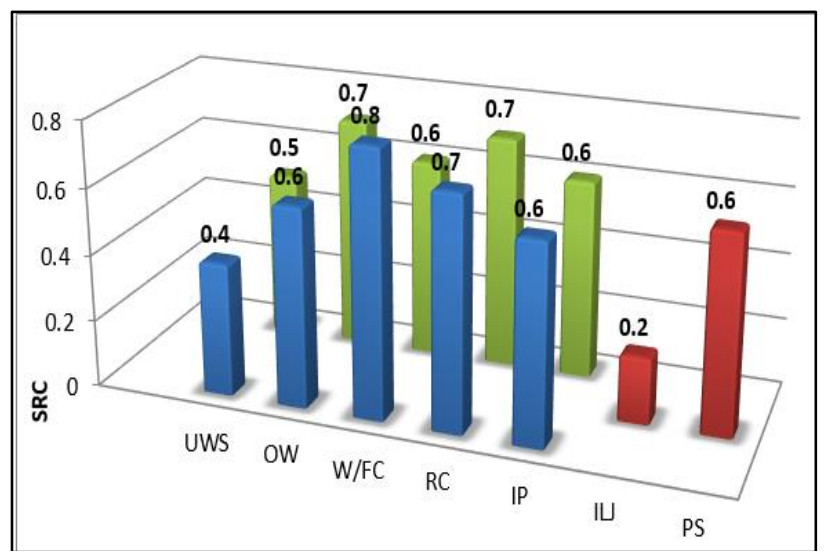

Fig. 1: Showing the correlation between SRC and stressors of work related stress questionnaire as a whole

\section{Discussion}

Stress and emotional disturbance among doctors is emerging problem worldwide. Many studies have reported high level of stress among health-care professional. (G. Shobha \& A. Lakshmi, 2014). ${ }^{11}$ High exposure to the stressful event among medical professional may manifest itself in several different outcomes including depression, anxiety, self-doubt, loss of sleep, impaired immune function, elevation of cardiovascular risk factor and burnout. Stress in health care profession is unavoidable thus we need to identify the stressors and equip the doctors with strategies to deal with stress. Stress in theworkplace reduces productivity, and makes people ill in many ways, evidence of which is still increasing. Doctors experience stress at work that has negative consequences both to the individual and the organization. ${ }^{12}$ Stress level among doctors were found to be of moderate level with regard to work and also in day today life. These findings are supported by Khaula Atif (2016) as in his study "Job satisfaction among doctors" he found that doctors face enormous stressors in personal and professional life but satisfaction at job is vital to attain superlative quality of work. Doctor's behavior with peers and physician-patient relation is largely dependent upon level of their job satisfaction. ${ }^{13}$

The present study reflects that stress is correlated with work stress. It means that if we do not cope well with stress, it will further affect our work and will lead to more stress. Research continues to show their unsatisfied situation with various aspects of work (especially professional relations and communication at work), is very much related to how work makes them feel, and this is even more so than how much they get paid. Exploring this supplementary may offer some insight into the problems and may possibly offer us some solutions..$^{14,15}$

The hospital authorities should create cogenial atmoshere and ensure proper recognition to the practioners. Hospital authorities and government can reduce the level of stress among the practioners and edventually that efforts help to improve the quality of healthcare system and patient's satisfaction. ${ }^{16}$ The medical curriculum, particularly in developing countries should be strengthened with courses such as administration and financial management. ${ }^{16}$ Prevention and treatment are essentially parallel efforts, including greater job control by the individual worker, group meetings, better up and down communication, more recognition of individual worth job redesign, flexible working hours, full orientation to job requirements, available assistance programs and adjuvant activity. ${ }^{17}$ Health and life insurance policies are still not popular with some of our colleagues and they should be encouraged. ${ }^{18}$ The government need to take necessary steps to provide financial assistance, subsidies and bank loan which will help the pactioners to improve the overall infastructure facilities. ${ }^{19}$ Stress coping programs should be introduced to provide the relevant way of dealing with work stress. Teaching stress related skills such as the instant calmness techniques can also help them to reduce stress and work stress. ${ }^{20}$ While addressing work related stress, it can also be a vehicle for positive change, for better and more dynamic relationships at work and for increased resourcefulness and efficiency. Therefore, it is suggested that doctors should be encouraged to maintain balance in life, work timings, professional and personal relationships, health issues, relaxation, and fun-plus the resilience to have a dialogue with organization.

\section{Conclusion}

Finally it can be concluded from the present study that the senior doctors are more stressed therefore they are needed to develop an improved understanding about work stress's sources. For depth of the study some coping strategies have been pointed out so that present $\&$ future doctors can work efficiently.

1. Now stress cannot be avoided and it is not healthy even for a doctor to avoid medically genuine stressing moments because this is what for he is needed. So it's better let him apply following guidelines:

a. Learn to say NO. 
b. Avoid people who stress you out.

c. Take a control of your environment.

d. Avoid HOT-BUTTON topics.

e. Narrow down TO-DO list.

2. When situations cannot be avoided, try to alter it. Figure out what can be done to change things so that problem doesn't present itself in future and that involves the changing the way of communicate and operate in your daily life like wise:

a. Express your feelings instead of bottling them-up.

b. We willing to comprise.

c. Be more assertive.

d. Manage your time batter.

3. Do not try to control the uncontrollable stressors. It can be adapted to stressful situations and regain a sense of control by changing expectations and attitude for that we need to apply some points:

a. Reframe the problem.

b. Look at the priorities first.

c. Adjust your standards.

d. Focus on the positive.

4. Stress can be reduced by nurturing yourself. If you make a time for fun and relaxation you will be in a better place to handle life's stressors when inevitably come.

\section{References}

1. Narayan. S, Ruwaidha. R, Nusrath. F.S, Fathima. F, Thandavamoorthy. G, Hegde. S. Perceived stress levels and its sources among doctors and nurses working in a tertiary care teaching hospital; Kanchipuram, Tamilnadu. N J Comm Med. 2016;7(7):603-8.

2. Hans Selye and McGraw-Hill. The stress of life. Rev. Ed. New York: McGraw-Hill. 1978. ISBN 9780070562127.

3. Cheyenne. C and Michael. N. CSUN Students to Learn How to Deal with Stress and Sleep Deprivation. Union California State University. 818;677:2875 .

4. Aswathappa. K and Reddy S.G. Management \&Organizational Behavior. New Delhi. 2008;4:267-28.

5. Alaxendra.S. Bornout in the hospital: why doctors are setup for stress. Workplace Health and Safety
Queensland. Time and health. 2014.

www.worksafe.qld.gov.au]

6. Demir F, Pýnar AY, Erbas M, Özdil M, Yapar E. The Prevalence of depression and its associated factors among resident doctors working in a training hospital in Istanbul. Turk J Psychiatry. 2007;18:31-37.

7. DHHS (NIOSH).Guide-lines for protecting the Health and Safety of Health Care Worker. 1988;88-119.

8. Baba I. Workplace Stress among doctors in government hospital: An empirical study. Int J Multidisc Res. 2012;2(5):208-20.

9. Balch, C.M., J.A. Freischlag and T.D. Shanafelt. Stress and burnout among surgeons: Understanding and managing the syndrome and avoiding the adverse consequences. Arch. Surg. 2009;144:371-76.

10. Srivastava R, Aggarwal A, Sangeeta. To study and compare the stress pattern in school going adolescent children from rural and urban background. Thesis awarded (unpublished) for the degree of MD Pediatrics, Santosh University, Ghaziabad, Uttar Pradesh, India. 2011.

11. G. Shobha and A. Lakshmi. A study on job stress among medical practitioners. Asian J Sci Res. 2014;7(5)488-500.

12. Shreedevi D. Stress Management among health care professionals. Int. J Res Bus Manag. 2013;1(3):37-48.

13. Khaula A, Habib U.K, Muhammad Z. U, Farrukh S. S, and Abdul L. Prevalence of anxiety and depression among doctors. Pak J Med Sci. 2016;32(2):294-98.

14. Swami MK, Mathur BK, Pushp BK. Emotional intelligence, perceived stress and burnout among resident doctors: An assessment of the relationship. Nation Med J Ind. 2013;26(4):210-13.

15. Felton JS. Burnout as a clinical entity-its importance in healthcare workers. Occup Med (Lond). 1998;48:237-50.

16. Andhale $S$, and AlmelT. Sleepless city getting more anxious by day too: Doctors. Delient Media Corporation Ltd. 2016 may;http://dnai.in/dmdZ.

17. Jane Barker.Mental health of among doctors- the elephant room?. 2017Available as https://tomedicinewithlove.com/

18. Lee FJ, Stewart M, Brown JB. Stress, burnout, and strategies for reducing them. Can Fam Physici. 2008;54:234-35.

19. Devi U.T.A Study on Stress Management and Coping Strategies With Reference to IT Companies, Hyderabad, India. J Inform Techno Econo Dev. 2011;2(2):30-48.

20. Familoni.O.B. An overview of stress in medical practice. Afr Health Sci. 2008;8(1):6-7. 